This item was submitted to Loughborough's Research Repository by the author.

Items in Figshare are protected by copyright, with all rights reserved, unless otherwise indicated.

\title{
Numerical modelling of the compression-after-impact performance of a composite sandwich panel
}

PLEASE CITE THE PUBLISHED VERSION

http://dx.doi.org/10.1177/1099636215576475

\section{PUBLISHER}

SAGE Publications / @ The Author(s)

VERSION

AM (Accepted Manuscript)

\section{PUBLISHER STATEMENT}

This work is made available according to the conditions of the Creative Commons Attribution-NonCommercialNoDerivatives 4.0 International (CC BY-NC-ND 4.0) licence. Full details of this licence are available at: https://creativecommons.org/licenses/by-nc-nd/4.0/

\section{LICENCE}

CC BY-NC-ND 4.0

\section{REPOSITORY RECORD}

James, Chris T., Andrew Watson, and Paul Cunningham. 2015. "Numerical Modelling of the Compressionafter-impact Performance of a Composite Sandwich Panel”. figshare. https://hdl.handle.net/2134/17238. 


\title{
Numerical Modelling of the Compression-after-Impact Performance of a Composite Sandwich Panel
}

\author{
Chris T James*, Andrew Watson, Paul R Cunningham \\ Department of Aeronautical and Automotive Engineering, \\ Loughborough University, Epinal Way, Loughborough, Leics', LE11 3TU, UK \\ *Author for correspondence: c.james@lboro.ac.uk
}

\begin{abstract}
A numerical model for the quasi-static indentation and compression-after-impact behaviour of a composite sandwich panel is presented, using cohesive surfaces for inter-laminar damage prediction. Intra-laminar damage and core crushing is also included. The models show generally good agreement with experimental results for residual strength, performing best when two cohesive surfaces are used in the impacted skin, but tend to over-estimate the undamaged panel strength. Damage extent predictions from the indentation phase of the analysis are often quite poor, but do not necessarily correlate with the accuracy of the strength estimates. The model provides a promising basis for further development.
\end{abstract}

\section{Keywords}

Numerical modelling; composites; sandwich panels; CAI; damage modelling

\section{Introduction}

Sandwich panels featuring composite skins and low-density cores are seeing increasing use in aerospace, marine and other industrial applications due to their improved specific strength and stiffness, and damage resistance, as compared with traditional monolithic composite structures [1]. However, they remain highly vulnerable to significant reductions in strength resulting from lowvelocity impact damage [1]. An example would be the damage resulting from a tool dropped onto a panel during maintenance. Particularly significant is Barely Visible Impact Damage (BVID), whereby there is little obvious damage at the surface, but with significant damage being present underneath. The consequence of this damage for the residual strength of sandwich panels has been extensively researched. For example, Zhou \& Hill, in their study investigating the Compression-after-Impact (CAI) strength of composite sandwich panels, observed a reduction in strength of up to $50 \%$ of the undamaged strength for impact energies at the threshold of BVID [2]. Damage from impact primarily takes the form of core crushing, fibre fracture and delamination in the impacted skin [3], of which delamination is a particularly significant damage mechanism [4]. Compressive testing is not the only measure of a damaged structure's residual strength, but it is considered the most critical load case for an impact-damaged structure [4].

Numerical modelling is an extremely useful tool for designers, as it eliminates much physical testing during design, prototyping and validation of new structures. One specific advantage for modelling compression problems is that it can remove some of the uncertainty that results from experiments. Data scatter and poor repeatability in CAI experiments is a well-documented problem [5,6], due to 
compressive failure modes being dominated by elastic instability, with their inherent sensitivity to structural and experimental imperfections [7]. This uncertainty results in a degree of inefficiency in structural design as higher factors of safety are required to provide confidence using composites over traditional metallic samples (for example, in NASA's standard for space vehicles, a factor of two is required for composite materials with discontinuities compared to a factor of 1.4 for metallic structures, with experimental verification mandatory for the former [8]). However, modelling impact and CAI problems is very demanding due to the complexity of damage and failure in composite materials, and of modelling dynamic impact events in general. Accurate prediction of damage and failure in composite materials remains an area of considerable interest $[9,10]$, and there remains no standard approach for evaluating the CAI strength of composite sandwich panels [11].

A common approach to predicting the CAI strength of a sandwich panel requires impact tests to be performed, and the resultant damage to be measured. The damage is then entered into a numerical model as an elastic inclusion, with stiffness reductions applied as necessary. Examples of this method include the work of Lacy \& Hwang [6,11] and McQuigg et al [12]. The latter work included progressive damage and failure in the skins. Czabaj et al $[7,13]$ and Lee et al [14] followed a different approach, whereby damage is induced in the model via a Quasi-Static Indentation (QSI) loading, prior to applying the compressive loading. Both of these models use an explicit honeycomb core geometry; that is to say the actual cellular geometry was applied. Czabaj also included a progressive damage response in the skins. None of the above mentioned models included delamination initiation and propagation as a specific feature. For example, in the work of Lacy \& Hwang, delamination caused by impact damage was measured and allowed for by an elastic inclusion, but was unable to propagate under compression. The accuracy of the above-mentioned models varied significantly, and often the predictions made for CAI strength would be of only moderate accuracy.

Delamination and its effect on the compressive strength of composite structures can be successfully simulated using the cohesive zone model. An example is the work of Gonzalez et al on the numerical modelling of CAI strength in monolithic composite plates [5]. This work was particularly advanced, featuring extensive use of cohesive interfaces between plies, user-specified intralaminar failure prediction and damage induced via a dynamic impact event. Good agreement with experimental results was found, but at considerable computational cost. The cohesive zone model has been applied to sandwich panels, for example, by Gopalakrishnan et al [15] in studying skin-core debonding in a cantilever beam. However, to the best of the authors' knowledge, this technique has not yet been applied to interlaminar delamination in a sandwich panel subject to a damaging transverse load and subsequent compressive loading.

A numerical model, built using the commercial FE software Abaqus/Explicit is presented herein that allows for the formation and propagation of delaminations in the impacted skin of a sandwich panel subject to a quasi-static indentation, followed by edge compression. The influence of this damage mechanism is used in conjunction with the Hashin composite failure criteria, and a simple plasticity model to capture core crushing. This model is prepared using material and panel configuration data from an experimental study by Czabaj et al [7,13]; the results from this study are used for comparative purposes. The predicted and measured damage extents will also be compared, to ascertain whether there is a link between the quality of the damage prediction and the accuracy of the strength estimate. 


\section{Czabaj, Singh et al experimental studies}

A number of panel configurations and layups were studied by Czabaj et al [7,13], using panels with carbon-epoxy skins (IM7/8552) and aluminium honeycomb core (HexWeb CR-III, 3.2mm cell size, 5052 aluminium alloy). This model simulates the the 'Q1-C1', 'Q1-C2' and 'Q2-C1' configurations indicated in Czabaj et al. $Q 1$ and $Q 2$ relate to two of the quasi-isotropic lay-ups used by Czabaj et al, with lay-ups of [45/0/-45/90 $]_{S}$ and [45/-45/0/90 $]_{S}$ respectively. $C 1$ and $C 2$ correspond to two of the cores used in the Czabaj et al study, both with density $49.7 \mathrm{kgm}^{-3}$, but with thicknesses of $25.4 \mathrm{~mm}$ and $16.5 \mathrm{~mm}$ respectively. The planar dimensions are $178 \times 152 \mathrm{~mm}$ for all panels. Only the crosssectional area of the skins is used for the strength calculation: with a nominal ply thickness of $0.127 \mathrm{~mm}$, this gives a skin thickness of $1.016 \mathrm{~mm}$, for a total cross-sectional area of $3.08864 \times 10^{-4} \mathrm{~m}^{2}$. The ribbon direction of the honeycomb core and the $0^{\circ}$ plies in the skins are parallel to the longer of the panel's planar dimensions. This is also parallel to the loading direction in compression. Panels damaged with the smaller indenter tended to show lower residual strengths in the experimental investigation, perhaps due to fibre fracture during indentation, which was not caused by the larger indenter.

The initial damage is produced via quasi-static indentation due to an applied load, recreating the damage induced in sandwich panels during an experimental study by the Singh et al [16]. Two sizes of indenter, both hemispherical, are used here, with a suitable load applied to correspond with the onset of Barely Visible Impact Damage (BVID). For the $76.2 \mathrm{~mm}$ indenter, this load equalled $2800 \mathrm{~N}$. The smaller $25.4 \mathrm{~mm}$ indenter required a $1300 \mathrm{~N}$ load for BVID. Both cases are modelled here for each of the panel configurations stated above, as well as the undamaged (virgin) panels for each configuration, for nine models in total. During the quasi-static indentation, the panel was rigidly supported - that is to say, it was placed on a solid surface, with no additional constraint necessary. For the subsequent edge compression, the free edges of the panel were left unconstrained. The strength results from this study are included with the predicted strengths from the model in Table 2. Failure in the virgin panels tests was usually via microbuckling, shear fracture, or a combination thereof in the $0^{\circ}$ plies with subsequent fracture in the rest of the plies in a direction perpendicular to the loading direction [13]. The nature of the damage caused by the QSI varied depending on the skin and core configuration; from Singh et al [16], the Q2 lay-up experienced more delamination than the Q1 lay-up, due to the presence of $90^{\circ}$ changes in ply orientation. The panels with the thinner $C 2$ cores also experienced more delamination then those with the $C 1$ core, due to reduced load redistribution resulting in an effectively stiffer structural response. Finally, the larger indenter induced larger delaminations, though this conclusion is based on qualitative rather than quantitative assessments.

\section{Model Definition}

The model developed in the current work has the following features:

- The panel model has a single symmetry plane parallel to the compressive loading, so for efficiency, a half-model is used, with a symmetric boundary condition ensuring correct model behaviour. Note that in post-processing, the reaction forces must be doubled to give a true representation of the structural response.

- The analyses are performed as multistep analyses. A quasi-static transverse indentation is applied first, under load control. The indenter is then withdrawn and finally, after a pause step 
to facilitate redefinition of boundary conditions, a quasi-static edge compression is applied via displacement control to find the residual strength of the damaged panel.

- All steps use a dynamic explicit solver, due to the highly non-linear structural response arising from material damage and failure. The indentation load is applied at a rate of $1 \mathrm{MN} / \mathrm{s}$, and the CAI displacement is applied at a rate of $0.5 \mathrm{~m} / \mathrm{s}$. These loading rates represent a significant acceleration of the problem as compared to a true quasi-static analysis. The ruleof-thumb for simulating quasi-static loadings with a dynamic solver assumes that the response of the structure is quasi-static provided that the kinetic energy does not exceed $5 \%$ of the system internal energy [17]. The ratio between kinetic and internal energy falls well below this accepted threshold for these loading rates - a typical example here, Q1-C1-lg-3, has an energy balance of $0.02 \%$ in the indentation phase and $0.33 \%$ in the compression phase - so the quasi-static loading assumption can be considered valid. The peak load is taken as the point of reference in both steps, as the kinetic energy will inevitably spike at ultimate load, due to a loss of system equilibrium.

- Both the initial indentation and compression-after-impact loading are applied via rigid surfaces using a general 'all-with-self' contact interaction. This allows the load and displacement history for both steps to be generated by monitoring a single node that defines the surface. The rigid surfaces have small masses applied to the controlling nodes, to enable their use with the explicit solver, while minimising the effect of inertia.

- The cohesive surface interactions between surface pairs, forming the interlaminar interfaces for delamination prediction, are defined within the general contact definition, using the material data given in Table 1. There are two locations for the cohesive interface: configuration 1 places the surface at the third interface from the indented surface in the indented skin (between the $-45^{\circ}$ and $90^{\circ}$ plies in the $Q 1$ lay-up, and the $90^{\circ}$ and $0^{\circ}$ plies in the Q2 lay-up). This surface is denoted as 'cohesive surface 1' in Figure 1. Configuration 2 places the interface at the fifth interface from the indented surface (between the $90^{\circ}$ and $-45^{\circ}$ plies in the Q1 lay-up, and the $0^{\circ}$ and $90^{\circ}$ plies in the Q2 lay-up); this surface is denoted in Figure 1 as 'cohesive surface 2'. There is also a third configuration presented here, which includes both of the above-mentioned cohesive surfaces. These locations have been chosen because delamination is expected to occur at a location where there is a change in fibre orientation [16].

- The skins are perfectly bonded to the core using tie constraints. The sets used to define the tied regions are selected such that a region around the edges of the mated parts are treated as unconstrained, to avoid clashes with the boundary condition definitions.

- All boundary conditions are applied to sets defined at the assembly level. For convenience, these sets are defined by geometry.

- Skins are meshed using 8-node general-purpose continuum shell elements with reduced integration (SC8R). The composite lay-ups are defined using Abaqus' lay-up tool, with Hashin criteria used to model laminate damage initiation and evolution [18]. The core is modelled as a solid, using a homogenous orthotropic core model with crushing behaviour applied via a simple plasticity response. It is meshed using 8-node linear solid elements with reduced integration (C3D8R).

- The indented skin (which is split into two or three blocks to allow for the inclusion of the cohesive surface, depending on the configuration) has approximately 1 element every $0.46 \mathrm{~mm}$ on average, with the mesh density increasing significantly towards the indented region. This level of refinement is necessary for the cohesive surface to provide a reasonably accurate description of the initiation and propagation of the delamination. Indeed, to improve 
the delamination prediction would require even greater mesh refinement; for composite materials, the cohesive zone whereby damage is developing will typically be tenths of a mm in length, and it is recommended to have at least three elements in this region to produce an accurate cohesive response $[19,20]$. The mesh size chosen is a compromise solution, giving an acceptable load-displacement response without requiring excessive computational resources, which was verified via a mesh sensitivity study. The two cores are meshed with approximately 1 element/mm in the through-thickness-direction to ensure a good representation of the core crushing behaviour. The distal skin has a relatively coarse mesh, as its response is only of secondary importance in this particular model. In total, the models contain approximately 113,000 elements; the exception is the Q1-C2 model, which has approximately 94,000 elements, due to the thinner core. Model configuration 3, with the additional cohesive layer, has between approximately 138,000 and 119,000 elements, depending on the core thickness.

- The key data output is the reaction force and displacement at the compression surface's controlling node, and the system's kinetic and internal energies. The force and displacement of the indenter is gathered to confirm the required load level for the damaging event is reached. Full-field data is collected for the out-of-plane displacement, the stiffness degradation in the cohesive surface, indicating delamination, and intralaminar damage. This data is used to predict the extent of the damage induced by the indentation.

The model is shown schematically in Figure 1, showing load directions, boundary conditions, material orientations and interfaces. The meshed model (Q1-C1-lg-1), also showing the rigid surfaces used to apply the loadings, is shown in Figure 2. Note that degrees-of-freedom 1, 2 and 3 and displacements $u$, $v$ and $w$ act in the directions of the $x, y$ and $z$ coordinates respectively.

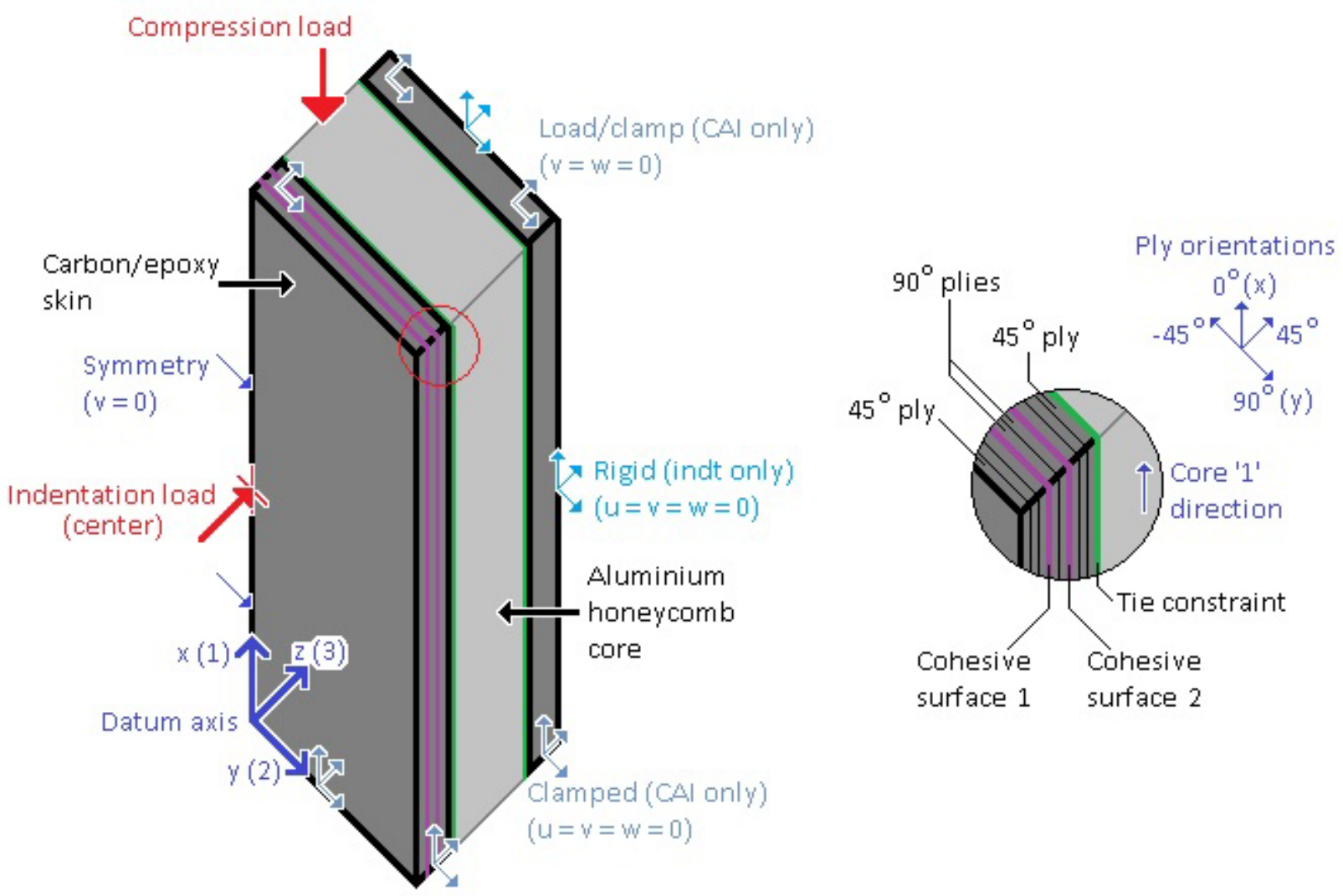

Figure 1. Schematic representation of the composite sandwich model, including boundary conditions, load and material directions and interfaces 
The material data used in the model is given in Table 1. The data is predominately taken from Czabaj (the 'corrected' data stated in [13] is used here). Some data has had to be taken from other sources, namely the core ultimate and crush strengths, taken from Hill [21], and the cohesive layer properties. There is no data provided by Czabaj for the interlaminar behaviour of this particular material, so the required data is predominately gathered from Camanho \& Davila [22] for a similar carbon-epoxy material. The exception is the normal opening and shear opening fracture energies, and the interlaminar shear strength, which are taken from Lloyd [23] for another carbon-epoxy composite. The mode-mix ratio used in the Benzeggagh-Kenane criterion [27] for fracture propagation is also taken from Camanho \& Davila, for yet another material system. This lack of consistency in the interlaminar material data must be regarded as a potential source of error, though it should be noted that the interlaminar performance of these different materials is reasonably similar. The data provided assumes a cohesive layer of 10 microns thick. Damage stabilisation is applied to the skin and cohesive models to ensure smooth behaviour. This is set at $1 \times 10^{-6}$ for all stabilisation parameters.

Table 1. Material Data for Numerical Model

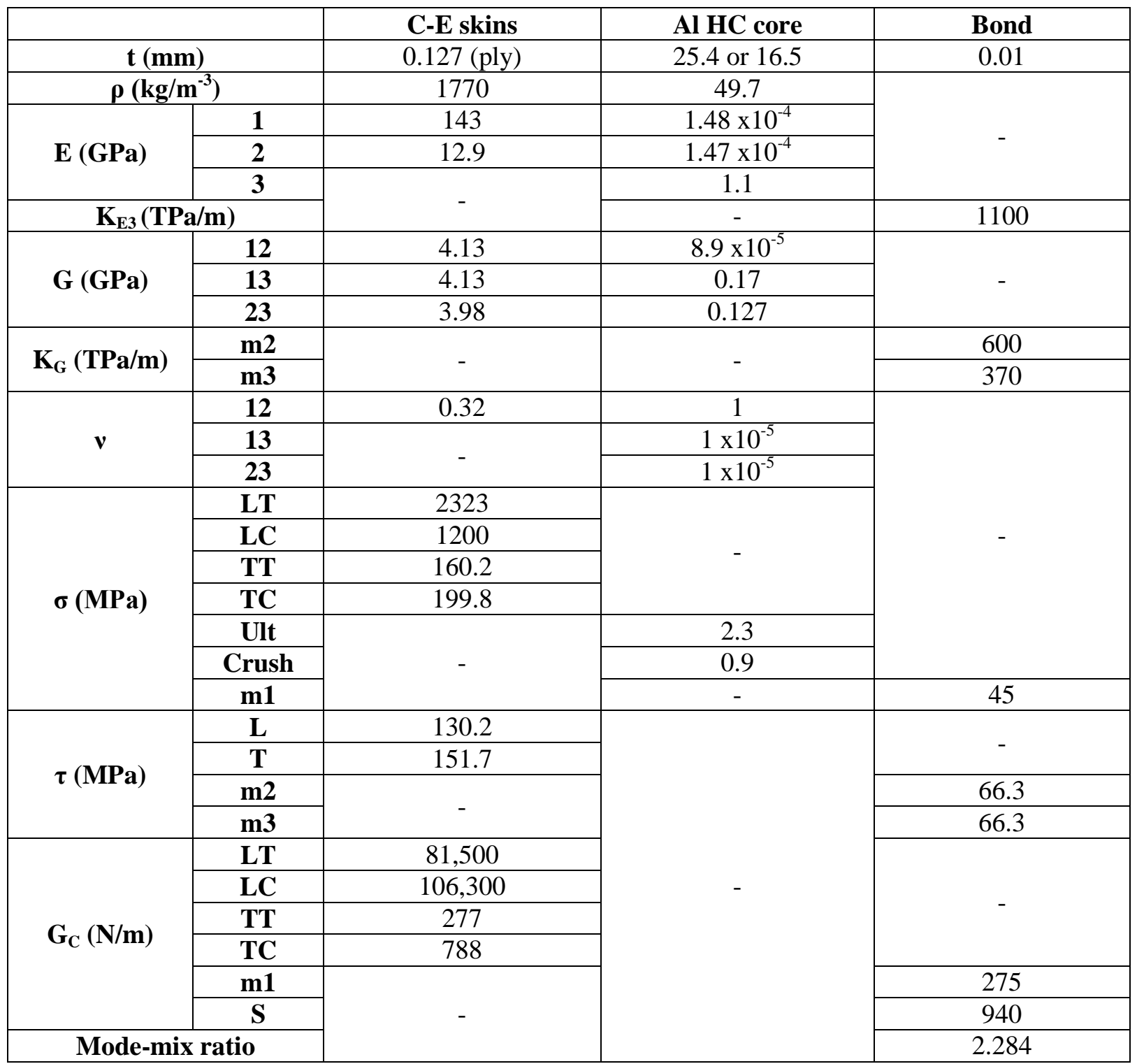


The implementation of Hashin's criteria for intralaminar damage initiation in Abaqus uses a combination of both the 1973 [24] and 1980 [25] formulations, suggested by Matzenmiller et al $[18,26]$, presented below. The work of Matzenmiller et al also provides the basis of the post-damage evolution material response.

Fibre failure:

$$
\begin{gathered}
F_{f}^{t}=\left(\frac{\sigma_{11}}{\sigma_{L T}}\right)^{2}+\alpha\left(\frac{\sigma_{12}}{\tau_{L}}\right)^{2} \quad\left(\text { For } \sigma_{11}>0\right) \\
F_{f}^{c}=\left(\frac{\sigma_{11}}{\sigma_{L C}}\right)^{2} \quad\left(\text { For } \sigma_{11}<0\right)
\end{gathered}
$$

Matrix failure:

$$
\begin{gathered}
F_{m}^{t}=\left(\frac{\sigma_{22}}{\sigma_{T T}}\right)^{2}+\left(\frac{\sigma_{12}}{\tau_{L}}\right)^{2} \quad\left(\text { For } \sigma_{22}>0\right) \\
F_{m}^{c}=\left(\frac{\sigma_{22}}{2 \tau_{T}}\right)^{2}+\left[\left(\frac{\sigma_{T C}}{2 \tau_{T}}\right)^{2}-1\right] \frac{\sigma_{22}}{\sigma_{T C}}+\left(\frac{\sigma_{12}}{\tau_{L}}\right)^{2} \quad\left(\text { For } \sigma_{22}<0\right)
\end{gathered}
$$

Where:

$\begin{array}{lll}\sigma_{11} & = & \text { nominal longitudinal (to the fibre direction) stress } \\ \sigma_{22} & = & \text { nominal transverse (to the fibre direction) stress } \\ \sigma_{12} & = & \text { nominal in-plane shear stress } \\ \sigma_{L T} & = & \text { longitudinal tensile strength } \\ \sigma_{L C} & = & \text { longitudinal compressive strength } \\ \sigma_{T T} & = & \text { transverse tensile strength } \\ \sigma_{T C} & = & \text { transverse compressive strength } \\ \tau_{T} & = & \text { transverse shear strength } \\ \tau_{L} & = & \text { longitudinal shear strength. } \\ \alpha & = & \text { formulation selection: this parameter takes a value }\end{array}$
non-zero value, the software includes the shear term in fibre tension from the 1980 criterion, with the contribution of this term to the material behaviour determined by the value of this coefficient. This parameter is set to zero for this model.

$F_{j}^{i} \quad=\quad$ failure criteria status, with the superscript $i$ and subscript $j$ referring to loading direction (tensile or compressive) and material component (matrix or fibre) respectively. Damage is initiated when the value this parameter reaches unity. 
For damage initiation in the cohesive layer, the quadratic nominal stress criterion is used, which accounts for the interaction between the tractions in the interface. This is given by:

$$
\left\{\frac{\left\langle t_{1}\right\rangle}{\sigma_{m 1}}\right\}^{2}+\left\{\frac{t_{2}}{\tau_{m 2}}\right\}^{2}+\left\{\frac{t_{3}}{\tau_{m 3}}\right\}^{2}=F
$$

Where:

$t_{1}, t_{2}, t_{3}=$ the tractions in mode 1 (normal opening), 2 and 3 (first and second shear directions) respectively.

$\sigma_{m 1} \quad=\quad$ mode 1 opening strength

$\tau_{m 2}, \tau_{m 3}=$ mode 2 and mode 3 shear strengths

F $\quad$ = failure criteria status; damage is initiated when this value equals unity.

For this cohesive model, the first and second shear fracture energies are assumed to be the same $\left(G_{2}{ }^{C}=G_{3}{ }^{C}=G_{S}{ }^{C}\right)$, so the Benzeggagh-Kenane criterion [27] is used to capture delamination propagation. Using this method, the fracture energy is thus given by:

$$
G_{C}=G_{m 1}^{C}+\left(G_{S}^{C}-G_{m 1}^{C}\right)\left\{\frac{G_{S}}{G_{m 1}+G_{S}}\right\}^{\eta}
$$

Where:

$G_{C} \quad=\quad$ critical fracture energy for the cohesive layer.

$G_{m 1}{ }^{c}=$ mode 1 opening fracture energy

$G_{S}{ }^{c}=$ shear mode fracture energy

$\eta \quad=\quad$ material parameter relating to the mode-mix ratio.

Both intralaminar and interlaminar damage evolution use a bilinear stress-strain law, where the strain in the element at failure is determined indirectly from the fracture energy input for the damage mode in question. The core crushing model is very simply implemented, by inputting a rapid drop in stress from maximum $\left(\sigma_{u l t}\right)$ to a constant stress value for the crushed core $\left(\sigma_{\text {crush }}\right)$ at approximately $0 \%$ plastic strain. In Table $1, E, K, G, v, \rho$ refer to the Youngs moduli of the skin/core, the elastic properties of the cohesive layer, the shear moduli of the skin/core, the Poisson ratio of the skin/core and the density of the materials, respectively. All this data is input directly into Abaqus and translated by the software into the equations given here. 


\section{Residual Strength Prediction}

The results from the models are presented in Table 2. The models are all run on a supercomputing cluster due to their size (with exception of Q1-C2-lg, which is run on an office desktop computer, see asterisk). Note that the CPU time indicated here is the equivalent time a single $\mathrm{CPU}$ would require to complete the analysis. The supercomputing cluster used for this work is split into processing nodes, with each node containing 12 processors. Included in this table are the mean CAI strengths for the configurations considered, as presented in the experimental results from Czabaj [13]. The suffixes vir, $l g$ and $s m$ indicate the virgin tests, and the CAI tests using damage induced by the large and small indenters respectively.

The CAI strength results vary between very good-to-fair depending on the panel, loading configuration and model configuration. For the purposes of this discussion, a "good" result has a percentage difference, as compared to the experiments, of $10 \%$ or less, and "very good" is $5 \%$ or less. These values

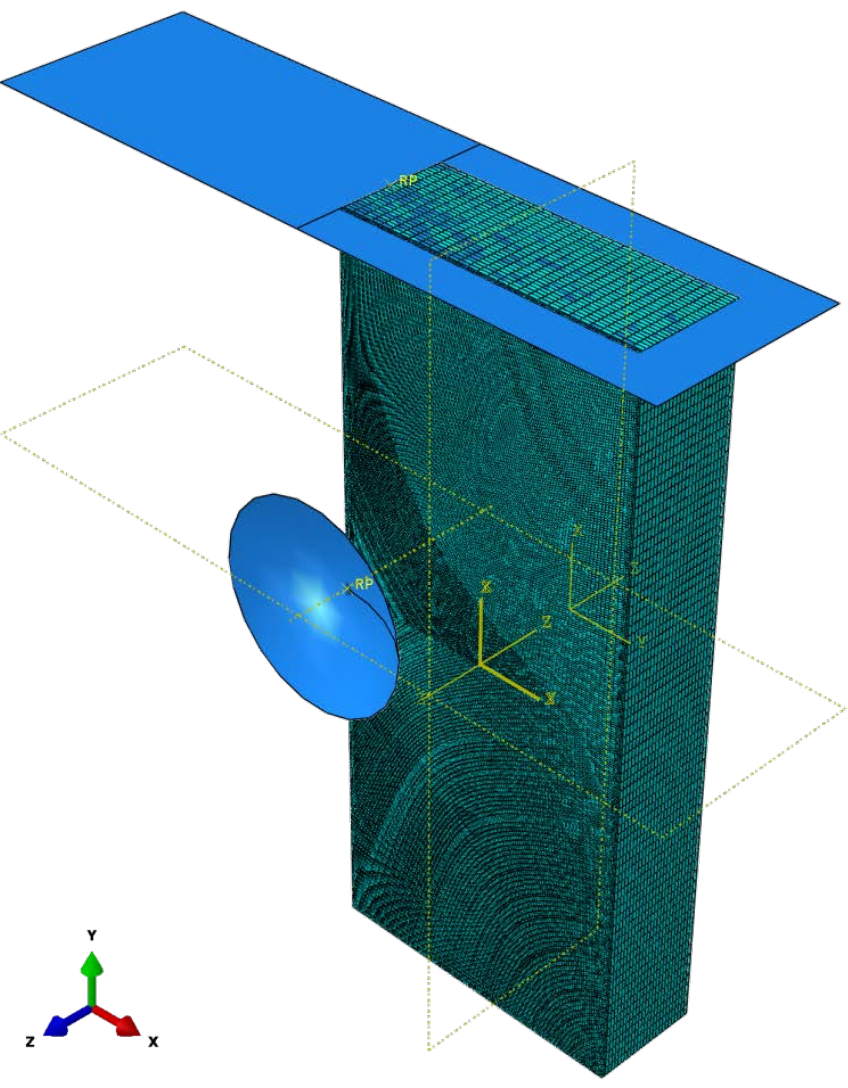

Figure 2. Meshed sandwich including rigid surfaces for load application (Q1-C1-lg-1) are based on the experimental variation in the experimental data; $5 \%$ is within experimental variation for most of the experiments, and $10 \%$ is within the maximum variation across all tests. The percentage difference is defined here as the percentage difference between the experimental strength result and the numerical models' strength estimate. Model configuration 1 gives the best residual strength predictions for the large indenter configurations whereas configuration 2 gives the best results for the small indenter configurations, and also the undamaged panel models. Perhaps unsurprisingly, configuration 3, using both cohesive surfaces, offers a 'best of both worlds' solution, with generally good agreement with the experiments for both CAI configurations, albeit at a significant computational cost (the runtimes using configuration 3 are approximately double that of the other two configurations). What is interesting to note is that the percentage residual strength prediction, if not necessarily the absolute strength values, is generally conservative, with the agreement between the numerical and experimental percentage residual strengths sometimes becoming weaker as the agreement between the absolute strength results becomes stronger. However, the residual strength prediction is necessarily dependant on the accuracy of the undamaged strength prediction. The model seems to perform best with the Q2-C1 configurations, as the presence of the cohesive surfaces at a $90^{\circ}$ ply boundary (where delamination is more likely) produces a physically more accurate response. The strength results tend to be non-conservative, as the model is an idealised representation of actual structures (that is to say, the geometry, loading and boundary conditions are all assumed to be perfect), and so lack the imperfection sensitivity present in real structures. 
Table 2. Residual strength results from numerical models and Czabaj et al experiments

\begin{tabular}{|c|c|c|c|c|c|c|c|c|c|c|}
\hline \multirow{2}{*}{\multicolumn{3}{|c|}{ Model* }} & \multirow{2}{*}{$\begin{array}{l}\text { CPU time } \\
\text { (hrs, mins) }\end{array}$} & \multirow{2}{*}{$\begin{array}{c}\text { Pmax } \\
(\mathbf{k N})\end{array}$} & \multicolumn{3}{|c|}{$\sigma_{\text {CAI }}(\mathrm{MPa})$} & \multicolumn{3}{|c|}{$\%$ residual strength } \\
\hline & & & & & Num & Exp & $\%$ error & Num & Exp & $\%$ error \\
\hline \multirow{11}{*}{ Q1-C1 } & \multirow{3}{*}{ vir } & 1 & 143h 28m & 144.5 & 467.8 & \multirow{3}{*}{400.1} & 16.9 & \multirow{3}{*}{\multicolumn{3}{|c|}{-}} \\
\hline & & 2 & 297h 52m & 101.5 & 328.7 & & -17.8 & & & \\
\hline & & 3 & 289h 23m & 150.4 & 486.8 & & 21.7 & & & \\
\hline & & & & & & & & & & \\
\hline & \multirow{3}{*}{$\lg$} & 1 & 276h 19m & 101.5 & 328.7 & \multirow{3}{*}{322.7} & 1.9 & 70.3 & \multirow{3}{*}{80.7} & -12.9 \\
\hline & & 2 & 263h 1m & 76.2 & 246.9 & & -23.5 & 75.1 & & -6.9 \\
\hline & & 3 & $472 \mathrm{~h} 29 \mathrm{~m}$ & 104.2 & 337.2 & & 4.5 & 69.3 & & -14.1 \\
\hline & & & & & & & & & & \\
\hline & \multirow{3}{*}{ sm } & 1 & 157h 48m & 116.4 & 376.7 & \multirow{3}{*}{293.6} & 28.3 & 80.5 & \multirow{3}{*}{73.4} & 9.7 \\
\hline & & 2 & 271h 41m & 86.6 & 280.3 & & -4.5 & 85.3 & & 16.2 \\
\hline & & 3** & $403 \mathrm{~h} \mathrm{4m}$ & 83.7 & 271.0 & & -7.7 & 55.7 & & -24.1 \\
\hline & & & & & & & & & & \\
\hline \multirow{11}{*}{ Q1-C2 } & \multirow{3}{*}{ vir } & 1 & $147 \mathrm{~h} \mathrm{40m}$ & 143.9 & 466.0 & \multirow{3}{*}{348.3} & 33.8 & \multirow{3}{*}{\multicolumn{3}{|c|}{-}} \\
\hline & & 2 & 125h 42m & 102.3 & 331.3 & & -4.9 & & & \\
\hline & & 3 & 282h 24m & 149.8 & 484.8 & & 39.2 & & & \\
\hline & & & & & & & & & & \\
\hline & \multirow{3}{*}{$\lg ^{+}$} & 1 & $160 \mathrm{~h} 29 \mathrm{~m}$ & 79.2 & 256.3 & \multirow{3}{*}{274.7} & -6.7 & 55.0 & \multirow{3}{*}{78.9} & -30.3 \\
\hline & & 2 & 146h 13m & 75.9 & 245.8 & & -10.5 & 74.2 & & -5.9 \\
\hline & & 3 & 278h 19m & 85.6 & 277.2 & & 0.9 & 57.2 & & -27.5 \\
\hline & & & & & & & & & & \\
\hline & \multirow{3}{*}{ sm } & 1 & 211h 52m & 93.1 & 301.3 & \multirow{3}{*}{247.3} & 21.8 & 64.7 & \multirow{3}{*}{71.0} & -8.9 \\
\hline & & 2 & 203h 24m & 76.3 & 247.2 & & 0.0 & 74.7 & & 5.2 \\
\hline & & 3 & 434h 3m & 76.5 & 247.5 & & 0.1 & 51.1 & & -28.1 \\
\hline & & & & & & & & & & \\
\hline & & 1 & $152 \mathrm{~h} \mathrm{45m}$ & 148.0 & 479.3 & & 7.9 & & & \\
\hline & vir & 2 & 134h 02m & 139.3 & 450.1 & 444.1 & 1.6 & & - & \\
\hline & & 3 & 291h 18m & 157.4 & 509.6 & & 14.7 & & & \\
\hline & & & & & & & & & & \\
\hline & & 1 & $276 \mathrm{~h}$ & 100.6 & 325.7 & & 8.9 & 68.0 & & 0.9 \\
\hline Q2-C1 & $\lg$ & 2 & 279h 47m & 98.7 & 319.5 & 299.1 & 6.8 & 70.8 & 67.3 & 5.2 \\
\hline & & 3 & $442 \mathrm{~h} \mathrm{43m}$ & 103.6 & 335.6 & & 12.2 & 65.8 & & -2.2 \\
\hline & & & & & & & & & & \\
\hline & & 1 & $165 \mathrm{~h} \mathrm{57m}$ & 124.0 & 401.5 & & 28.5 & 83.8 & & 19.1 \\
\hline & sm & 2 & 221h 10m & 107.5 & 348.0 & 312.4 & 11.4 & 77.2 & 70.3 & 9.7 \\
\hline & & 3 & $441 \mathrm{~h} \mathrm{20m}$ & 104.8 & 339.4 & & 8.6 & 66.6 & & -5.3 \\
\hline
\end{tabular}

*1 = cohesive surface 1 only;

2 = cohesive surface 2 only;

$3=$ both surfaces

** Minor adjustments to the mesh required for Q1-C1-sm-3 to avoid element distortion issues.

${ }^{+}$All Q1-C2-lg models run on a desktop machine using 3 cores. 
On the whole, the predictions for the undamaged panel strengths are moderately good at best when compared with the experimental results, becoming quite poor for the Q1-C2 panel; all the same, the numerical model produces strength predictions well within the 1.4 factor of safety recommended by NASA for uniform composite structures [8]. Generally, the undamaged strength predictions are noticeably less accurate than the CAI results produced using the same model set-ups, even when using the more general configuration 3 model. The already-mentioned problem of scatter in experimental data for edge compression of panels may be an influencing factor in this error. One peculiar result in Czabaj's study is that the compressive strength of the undamaged panels seems to be dependent on the lay-up in a manner that is not expected, as the Q1 and Q2 lay-ups have identical numbers of plies oriented to the $0 / 45 /-45 / 90^{\circ}$ axes [13]; this may be due to the increased tendency of delamination in the Q2 lay-up. Additionally, the Czabaj panels had skins co-cured with the cores, resulting in some waviness of the plies closest to the core, which in turn induces a degree of imperfection for which the model does not allow. It may therefore be more appropriate to treat the virgin panel numerical results as a theoretical upper-limit for panel strength. The noteworthy exception already identified is model configuration 2, which shows good agreement with the experimental strength results. The generally accurate structural response of the models is shown by stress-strain curves in Figure 3 to Figure 11.

A key limitation with all the models is the simple, homogenised core response. Singh et al [16] note that the core is the primary controller of the QSI indentation response, so inaccuracies in the core behaviour will inevitably affect the state of the damage prior to the CAI loading, and thus influence the ultimate strength. In spite of this, the CAI results are consistently good using model configuration 3 , regardless of panel and load configuration. Instead, the deficiency in the core model may be more significant in explaining the relative weakness of the model at predicting the undamaged strength of the panels, as the response of the virgin panels may be more sensitive to flaws in the core response in lieu of a pre-existing delamination. Future work is required to address this deficiency in the core model. Singh et al also note that, for the small indenter configurations, delaminations tend to be deeper in the plate, at the $5^{\text {th }}, 6^{\text {th }}$ and $7^{\text {th }}$ interfaces. This may explain why model configuration 2 , with the cohesive surface set deeper into the panel, gives improved results for the small indenter load cases over configuration 1 , where the cohesive surface is placed closer to the indented surface of the panel. Based on the improved results for the large indenter load cases using configuration 1, one could hypothesise that, for these cases, the delaminations that control the response of the panel occur closer to the indented surface. Without experimental data for the large indenter cases, it is not possible to state conclusively whether or not this is in fact true.

Regarding the failure mechanism, it is difficult to observe the propagation of damage due to the relatively low resolution of the field data output. However, for most configurations studied here, the model appears to show indentation growth (that is to say, the dent is becoming deeper, rather than wider) prior to final failure. Failure seems to usually occur via a rapid propagation of delamination across the width of the panel, resulting in delamination buckling. An example of this is shown in Figure 12a, for configuration Q1-C1-lg-1 (the top ply block is removed to show the cohesive surface). In a couple of cases, the dent depth gets smaller, but this does not appear to influence the final failure. Some panels also appear to undergo localised longitudinal compressive failure, as seen by a continuous line of elements across nearly the whole width of the panel that suddenly exceed the Hashin criteria's limit for this damage mechanism; this is shown for Q2-C1-sm-1 in Figure 12b. It is unclear for these panels whether it is the ubiquitous delamination growth or the local compressive damage that initiates final failure. As far as the model allows, the predicted onset and propagation of failure appears to agree well with the experimental observations for the panels studied. 


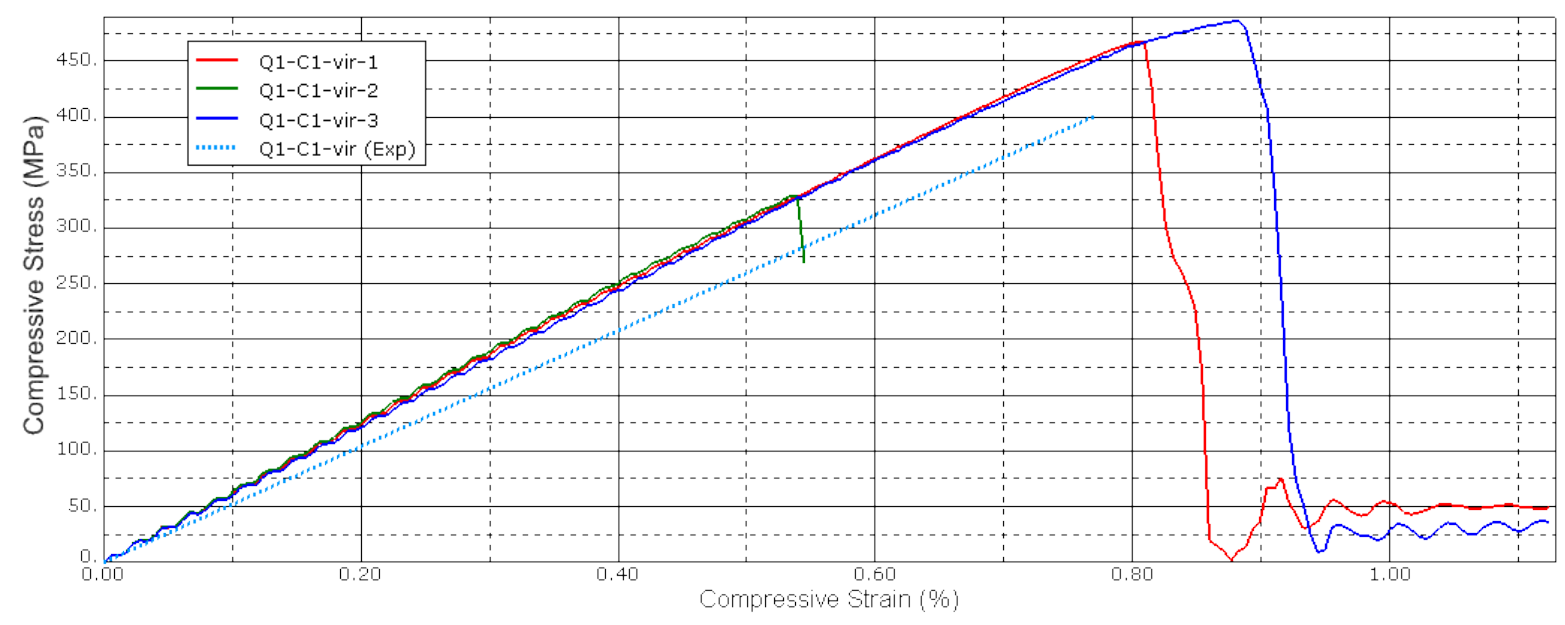

Figure 3: Stress-strain responses for the Q1-C1-vir panel models

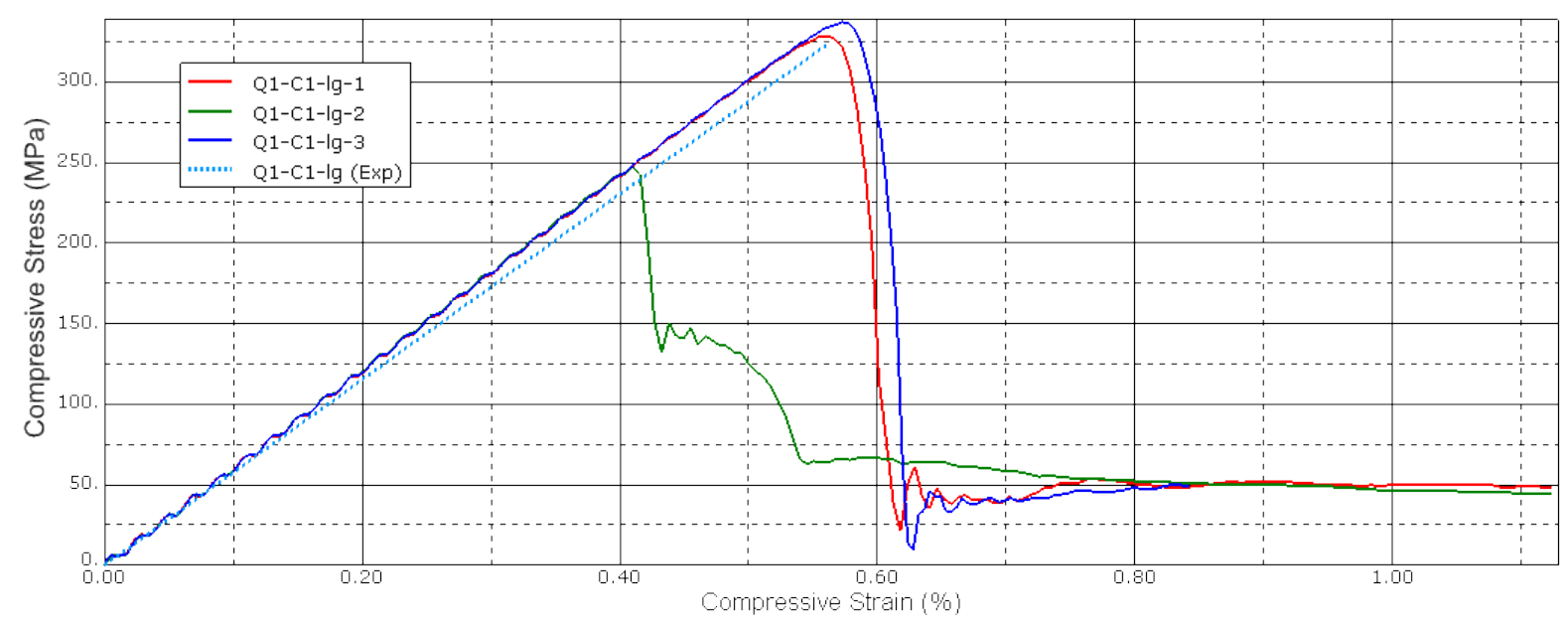

Figure 4: Stress-strain responses for the Q1-C1-lg panel models

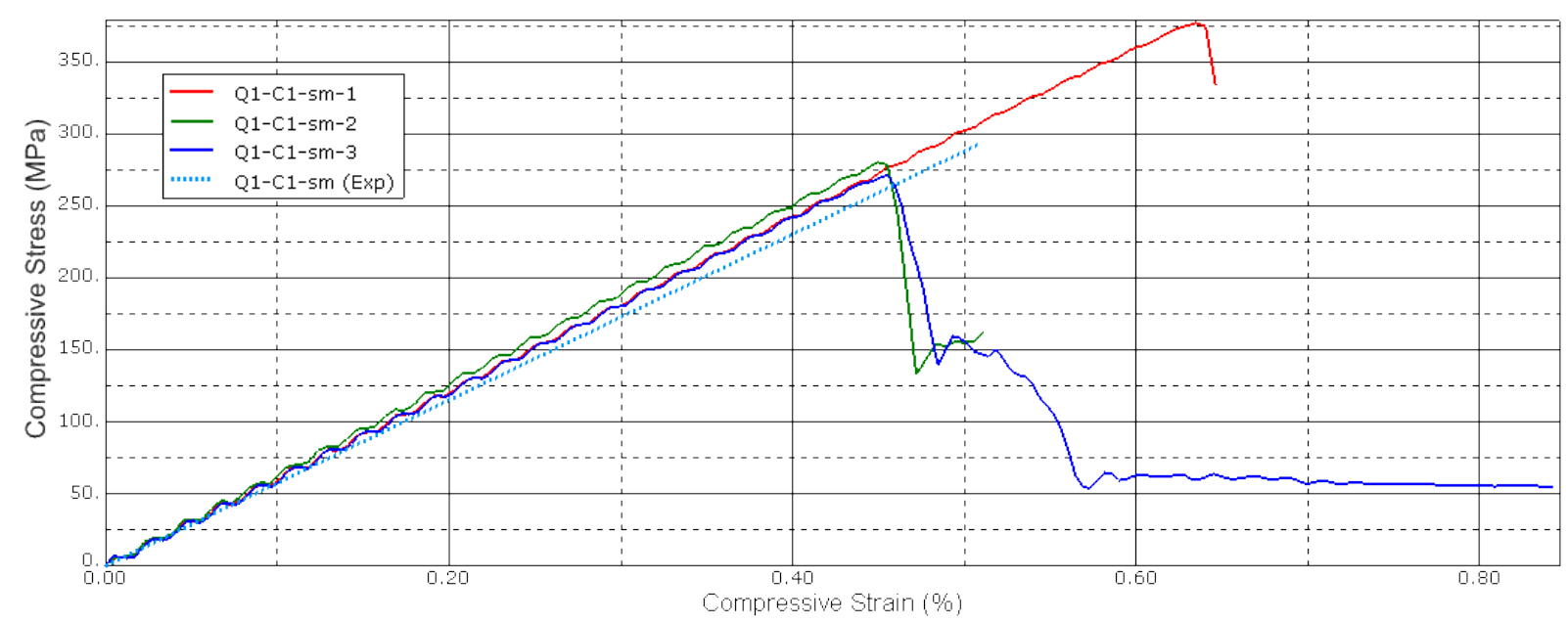

Figure 5: Stress-strain responses for the Q1-C1-sm panel models 


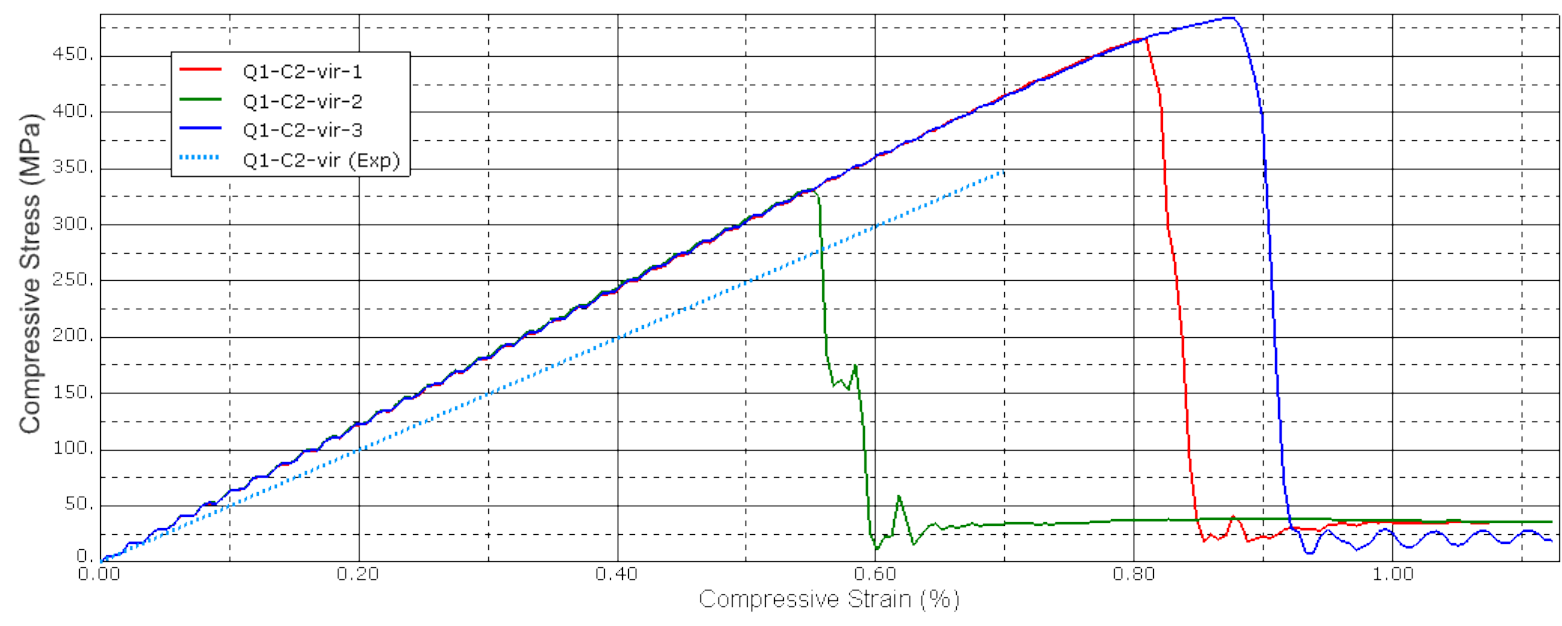

Figure 6: Stress-strain responses of Q1-C2-vir panel models

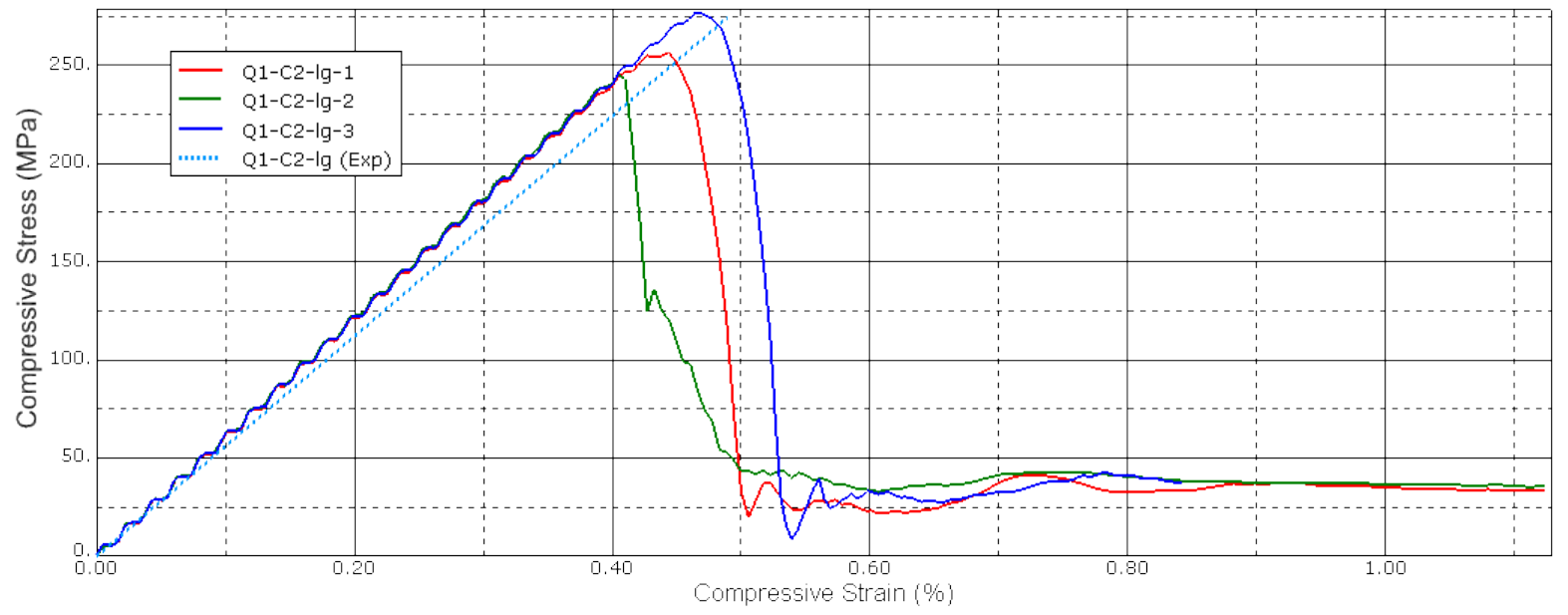

Figure 7: Stress-strain responses of Q1-C2-lg panel models

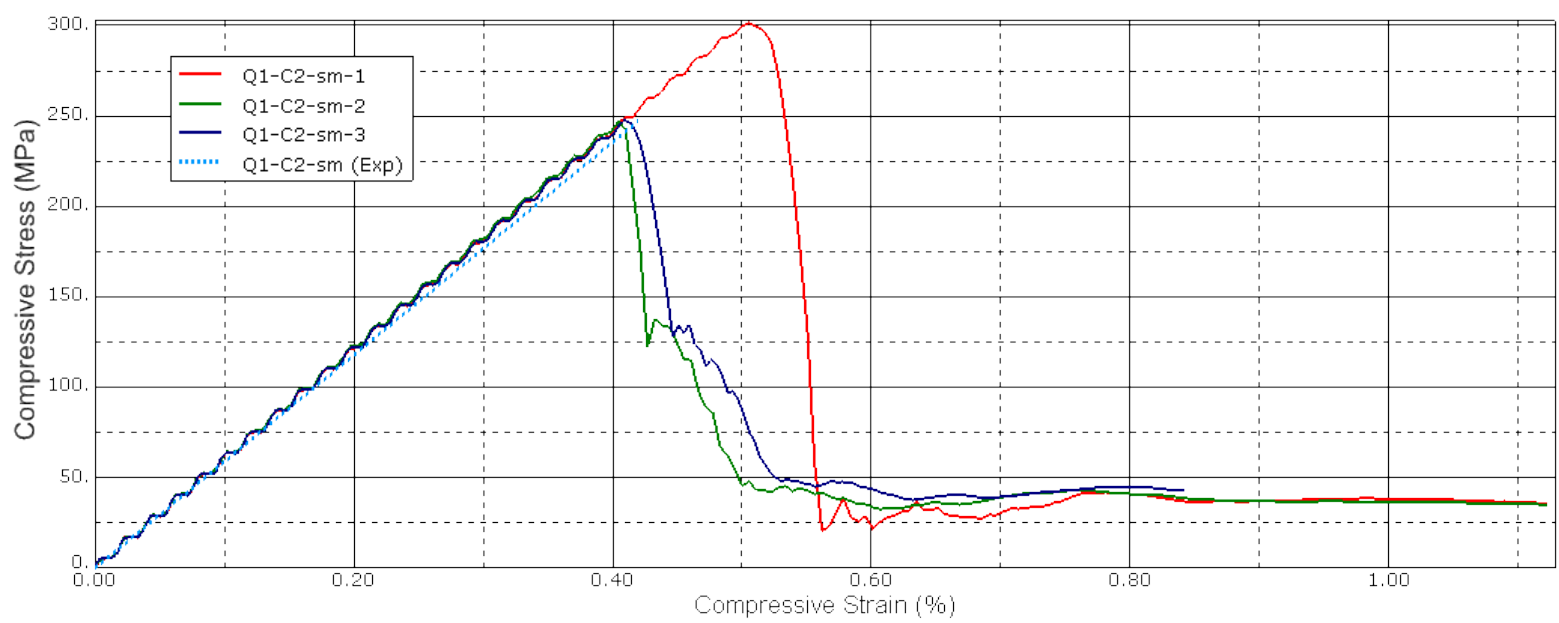

Figure 8: Stress-strain responses of Q1-C2-sm panel models 


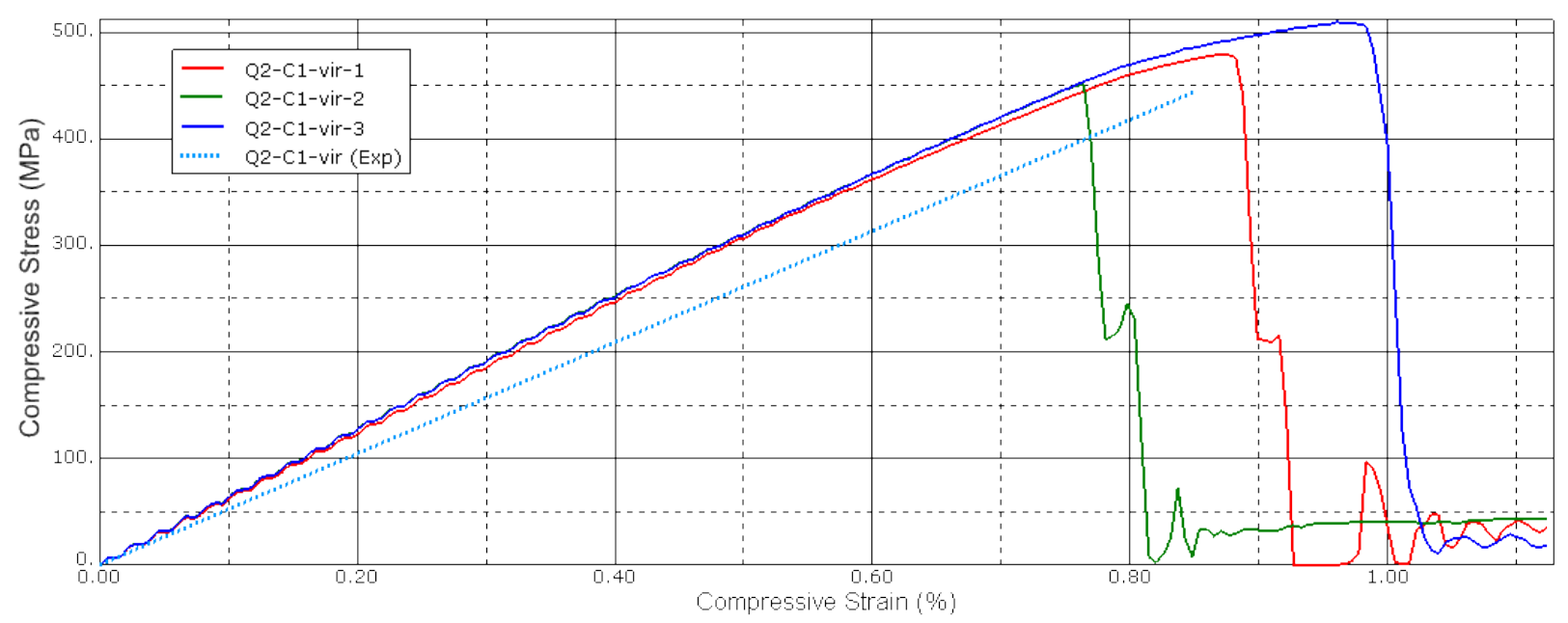

Figure 9: Stress-strain responses of Q2-C1-vir panel models

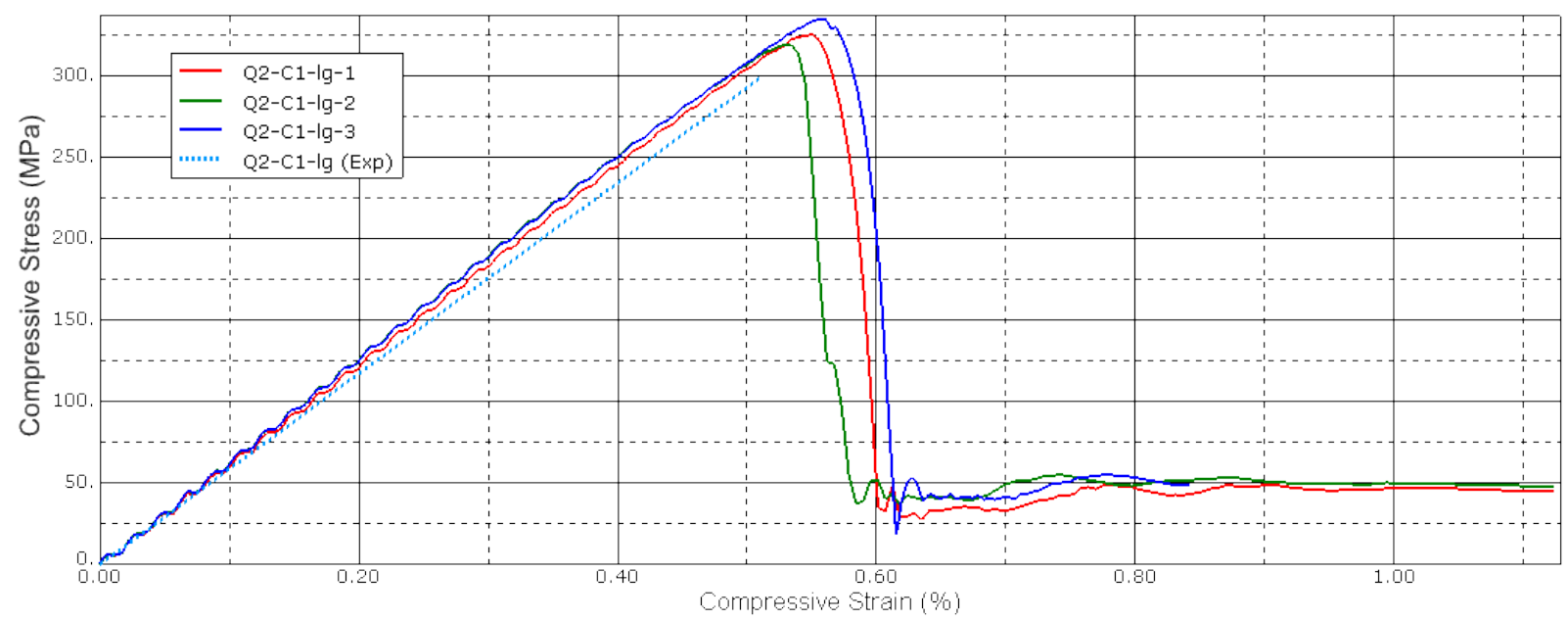

Figure 10: Stress-strain responses of Q2-C1-lg panel models

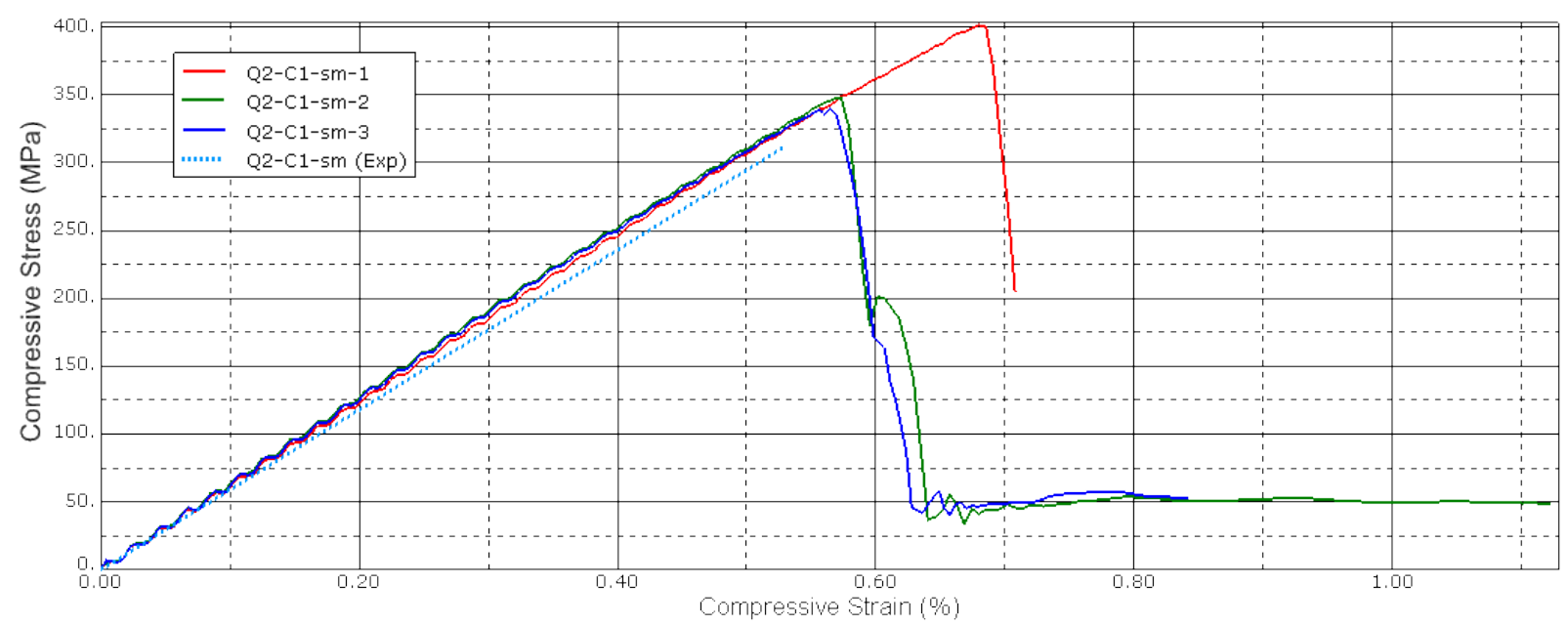

Figure 11: Stress-strain responses of Q2-C1-sm panel models 

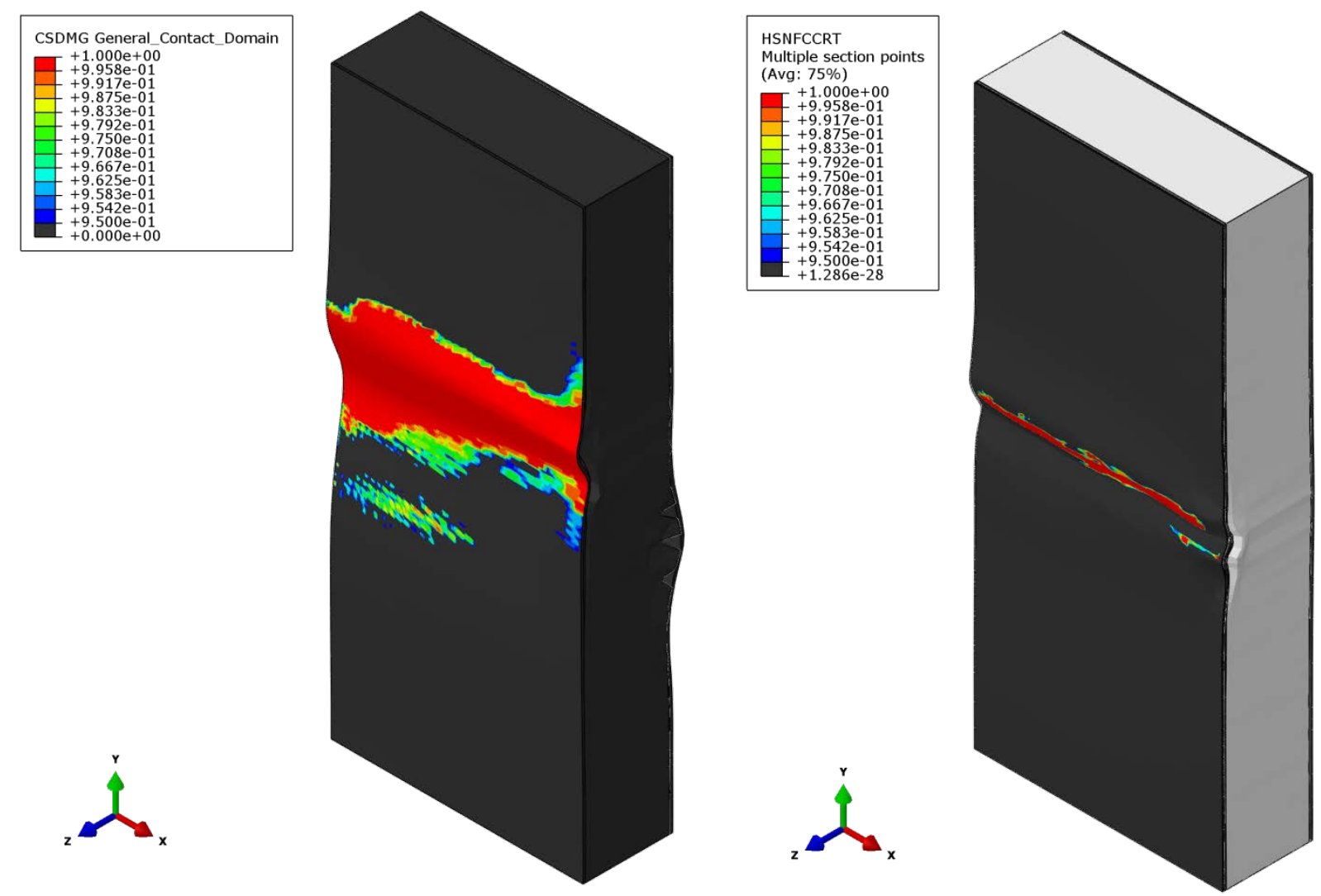

Figure 12. Sandwich panels at the point of final failure.

a) (left) Q1-C1-lg-1, showing typical delamination propagation and buckling delamination occurs when CSDMG $=1$.

b) (right) Q2-C1-sm-1, showing compressive failure of the fibres - fibre failure in compression occurs when HSNFCCRT $=1$

\section{Damage Extent Prediction}

To get a better understanding of the behaviour of the model, the predicted and experimentally measured damage geometries are presented in Table 3. Delamination is presented by Czabaj [13] by area for the small indenter cases only, and no core damage metrics are provided by Czabaj. The mean values from Czabaj for damage magnitude are presented here for comparison. Delamination is considered to have occurred in the model when the scalar stiffness degradation in the cohesive surface equals one, indicating complete separation of the two faces. The diameter of the dent is determined by considering the region where the depth of the dent exceeds $0.25 \mathrm{~mm}$ (the visible threshold for BVID is accepted at $0.5 \mathrm{~mm}$ [2], however, a smaller threshold is required here due to the small maximum dent sizes). The same lower limit is used to establish the depth and diameter of the crushed core region, as this approximately corresponds with the generation of significant plastic strain in the core, indicating permanent deformation in the core. The numerical damage sizes are estimated from the element sizes; based on the mesh seeds, 1 element approximately equals $0.46 \mathrm{~mm}$ in the skin, and $2.5 \mathrm{~mm}$ in the core. The core also has approximately 1 element/mm through-the-thickness. Due to the use of biased meshing to increase the mesh density in the indented region, these measures are average sizes and so are not perfectly accurate, but adequate for making broad comparisons between the experiments and the models. 
Table 3. Predicted and measured damage extents in the sandwich panels at the end of the quasi-static indentation phase

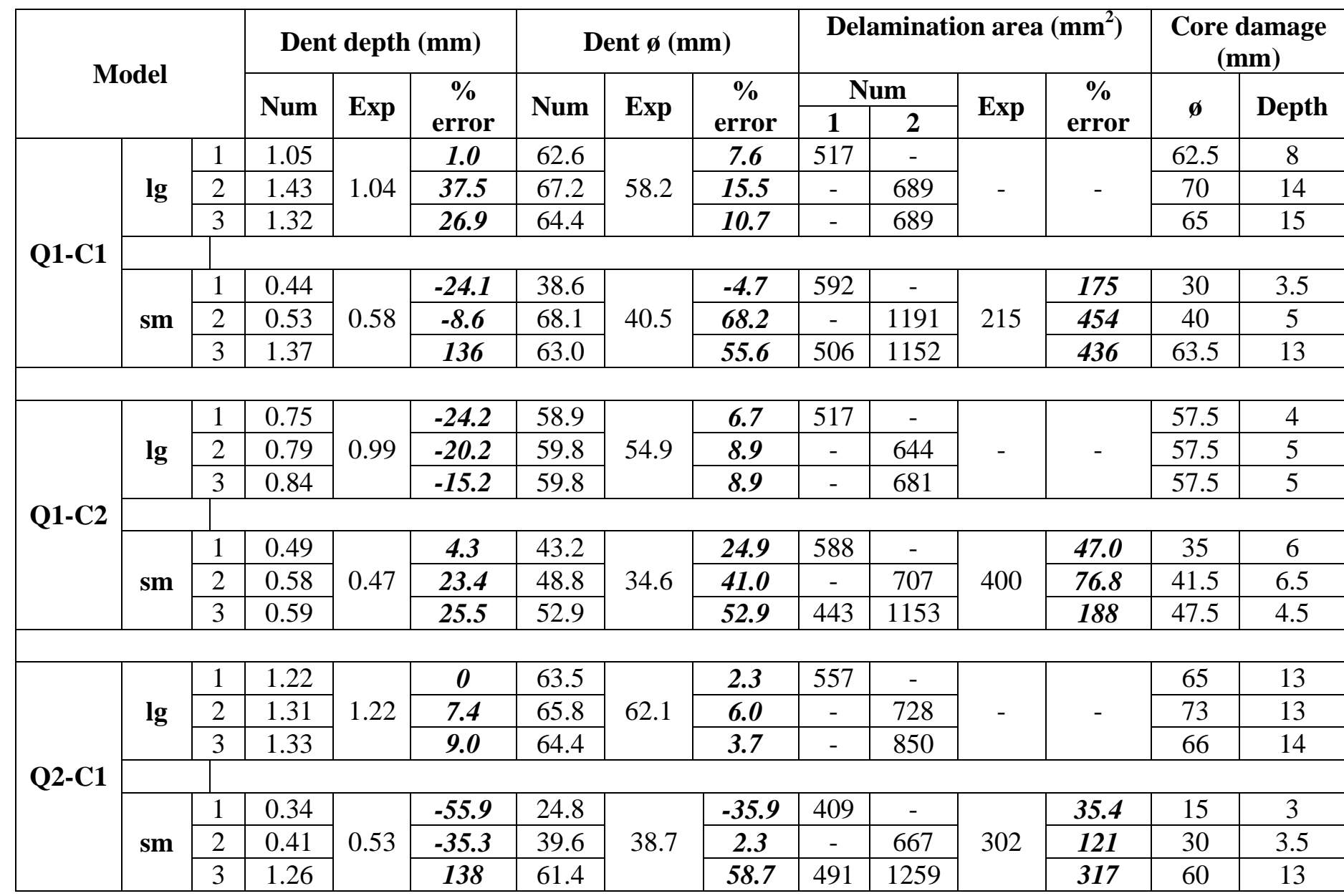

As with the strength results, the estimates for damage extent from the models vary significantly between configurations. The large indenter configurations generally show the best agreement with the experimental results for dent depth and extent, with model configuration 1 providing the best agreement across all panel configurations; as previously discussed, the large indenter models also tended to have the strongest agreement with the experiments for the residual strength, regardless of which model configuration was used. This suggests that the response of these configurations is controlled more by the damage in the skins, but without experimental data for delamination extent in the large indenter configurations, or core damage in general, this observation is by no means conclusive.

The small indenter models show poor agreement with the experiments for dent depth and extent, with the thick-core models (Q1-C1 and Q2-C1) being particularly poor. However, the model still produces acceptable strength results for this loading configuration. The discrepancy is particularly stark with model configuration 3, which shows very poor agreement for the dent depth and magnitude for most small indenter models, and yet in the main produces good agreement with the experimental results for residual strength. The small indenter case is also the only one where there is quantitative experimental data for the delamination extent; the model invariably over-estimates delamination by a significant amount. This leads one to conclude that the response of the small indenter configurations may instead sensitive to the accuracy of the core response model; without experimental data for the core damage 
extent, no comparisons are possible at this stage. Improving the core response was previously identified as an area for improvement (see 'Residual Strength Prediction').

Singh et al [16] state that, based upon qualitative assessment, the larger indenter induces a greater size of delamination than the small indenter, so it is possible that numerical delamination prediction is better for the large indenter models. Additional work is necessary to support this hypothesis. It is also noteworthy that the model does not capture the shape of the delamination accurately. Considering configuration Q1-C1-sm-1, it can be seen that the delamination in the model is approximately circular (see Figure 13), whereas in the experimental study it is broadly elliptical (the cohesive surface shown here corresponds with 'interface 3' in Figure 6 of [16]). This is to be expected, as the response of the other interfaces are not captured, thus removing their influence on the response of the interface under consideration here. Additionally, recall that the mesh may not be sufficiently fine to ensure an accurate estimate of the delamination size and shape (see 'Model Definition').

For model configuration 3, the delaminations in both interfaces tend be more of a 'squashed circle' shape, closer to the shape seen in the experiments, but all the same, the minor dimension in the numerically-derived delamination is much larger than the experimental results would suggest. It is interesting to note that with this model configuration, no delamination is detected after indentation for any of the large indenter models in the first interface (near the surface), and the deeper, second interface delamination is always the larger one in the small indenter models. This seems to contradict the experimental findings of Hwang \& Liu [28], who note that the near-surface delamination should be the largest after an impact event. Also noteworthy is the fact that the residual strength predictions for configurations 1 and 2 clearly demonstrate that the position of the cohesive surface (and thus the delamination) influences the strength, yet this effect seems to be negated once multiple delaminations are able to form. It should be restated that the material data for cohesive surface is taken from different sources for different materials, and thus may not be entirely representative for this particular material system (see ‘Model Definition').
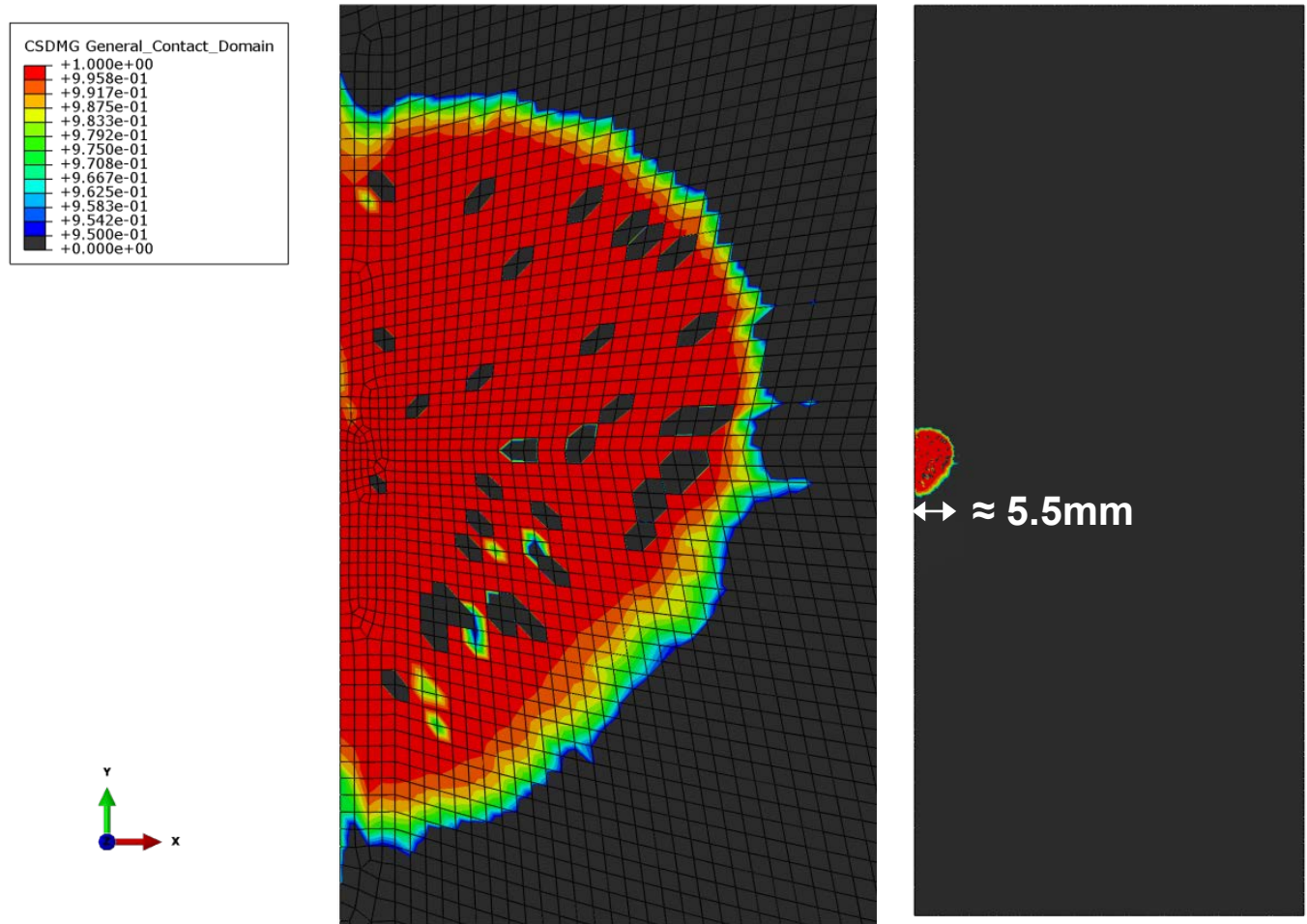

Figure 13. Delamination in Q1-C1-sm-1 after QSI (right: full panel view) 


\section{Conclusions}

A dynamic explicit numerical model for predicting the residual compressive strength of composite sandwich panels following a quasi-static indentation has been developed. The primary feature of this model is the addition of a cohesive surface interaction at a single interface in the impacted skin on the panel, to capture the formation and propagation of interlaminar delamination during the impact event and subsequent compressive loading. Intralaminar damage in the skins is included using the Hashin criteria, and a simple plasticity model captures core crushing. The model is then analysed for a number of sandwich panel and loading configurations as investigated by Czabaj et al $[7,13]$.

The model shows very good to fair agreement with the experimental results for the residual strength of the panels, with model configuration 3, featuring two cohesive surfaces, providing generally very good results for both large and small indenter configurations. The strength reduction factor from the models tends to be conservative, and the undamaged panel strength is usually over-estimated, often quite considerably. The accuracy of the damage extent predictions tend to be much more variable, and often quite poor, especially for the small indenter loading configuration. It is believed that the simplicity of the core model used here may contribute to the observed inaccuracy of the model for some configurations (particularly the undamaged panels), though this cannot be stated for certain due to the lack of experimental core damage data for comparison. Nevertheless, inclusion of a more comprehensive core damage model is considered a necessary area for further development. The lack of consistent material data for the cohesive interface for this material system may also contribute to the error. Additional enhancements to the model can include the inclusion of geometric imperfections and a more advanced intralaminar skin damage model (for example, the LaRC03/04 criteria [29,30]). With the availability of increased processing power, the mesh may also be further refined to improve the delamination prediction.

This work demonstrates the importance of accurately accounting for the formation and propagation of interlaminar delamination when simulating the structural response of composite sandwich panels. The model presented here provides a promising basis for further development, which may eventually be suitable for design studies.

\section{Funding Acknowledgment}

This work was funded by the Department of Automotive and Aeronautical Engineering at Loughborough University, as part of a $\mathrm{PhD}$ research project.

\section{References}

1. Abrate S. Localized Impact of Sandwich Structures with Laminated Facings. Applied Mechanics Review 1997;50(2):69-82.

2. Zhou G, Hill MD. Impact Damge and Energy-Absorbing Characteristics and Residual In-Plane Compressive Strength of Honeycomb Sandwich Panels. Journal of Sandwich Structures and Materials 2009;11:329-356. 
3. Zhou G, Hill M, Loughlan J, Hookham N. Damage Characteristics of Composite Honeycomb Sandwich Panels in Bending under Quasi-Static Loading. Journal of Sandwich Structures and Materials 2006;8:55-90.

4. Schubel PM, Luo J, Daniel IM. Impact and Post-Impact Behaviour of Composite Sandwich Panels. Composites: Part A 2006;38:1051-1057.

5. Gonzalez EV, Maimi P, Camanho PP, Turon A, Mayugo JA. Simulation of Drop-Weight Impact and Compression after Impact Tests on Composite Laminates. Composite Structures 2012;94:33643378.

6. Lacy TE, Hwang Y. Numerical Modelling of Impact-Damaged Sandwich Composites Subjected to Compression-after-Impact Loading. Composite Structures 2003;61:115-128.

7. Czabaj MW, Zehnder AT, Davidson BD, Singh AK, Eisenberg DP. Compression after Impact of Sandwich Composite Structures: Experiments and Modelling. 51st AIAA/ASME/ASCE/AHS/ASC Structures, Structural Dynamics and Materials Conference, Orlando, Florida.

8. Anon. Structural Design and Test Factors of Safety for Spaceflight Hardware. NASA Technical Standard 2008;NASA-STD-5001A.

9. Hinton MJ, Soden PD. Predicting Failure in Composite Laminates: the Background to the Exercise. Composites Science and Technology 1998;58:1001-1010.

10. Soden PD, Kaddour AS, Hinton MJ. Recommendations for Designers and Researchers Resulting from the World Wide Failure Exercise. Composites Science and Technology 2004;64:589-604.

11. Hwang Y, Lacy TE. Numerical Estimates of the Compressive Strength of Impact-Damaged Sandwich Composites. Journal of Composite Materials 2007;41:367-388.

12. McQuigg TD. Compression After Impact Experiments and Analysis on Honeycomb Core Sandwich Panels with Thin Facesheets. NASA, Langley 2011;NASA/CR-2011-217157.

13. Czabaj MW. Damage and Damage Tolerance of High Temperature Composites and Sandwich Composite Structures. , Cornell University, 2010.

14. Lee S, Ansari MZ, Wang N, Cho C. A Computational Study on Residual Strength of Sandwich Composite Panel. Advanced Materials Research 2012;393-395:521-525.

15. Gopalakrishnan K, Ramesh Kumar R, Anil Lal S. Cohesive Zone Modelling of Coupled Buckling - Debond Growth in Metallic Honeycomb Sandwich Structure. Journal of Sandwich Structures and Materials 2012;14(6):679-693.

16. Singh AK, Davidson BD, Eisenberg DP, Czabaj MW, Zehnder AT. Barely Visible Impact Damage Evaluation of Composite Sandwich Structures. 51st AIAA/ASME/ASCE/AHS/ASC Structures, Structural Dynamics, and Materials Conference, Orlando, Florida, 2010. p. 1-17.

17. Prior AM. Applications of Implicit and Explicit Finite Element Techniques to Metal Forming. J Mater Process Technol 1994;45:649-656.

18. Anon. Abaqus Analysis User's Manual (6.12): Dassault Systemes, 2012. 
19. Turon A, Davila CG, Camanho PP, Costa J. An Engineering Solution for Mesh Size Effects in the Simulation of Delamination using Cohesive Zone Models. Engineering Fracture Mechanics 2007;74:1665-1682.

20. Harper PW, Hallett SR. Cohesive Zone Length in Numerical Simulations of Composite Delamination. Engineering Fracture Mechanics 2008;75:4774-4792.

21. Hill MD. Damage Resistance and Tolerance Investigation of Carbon/Epoxy Skinned Honeycomb Sandwich Panels. , 2007.

22. Camanho PP, Davila CG. Mixed-Mode Cohesion Finite Elements for the Simulation of Delamination in Composite Materials. NASA 2002;NASA/TM-2002-211737.

23. Lloyd JC. Impact Damage and Damage Tolerance of Fibre Reinforced Advanced Composite Laminate Structures. , 2002.

24. Hashin Z, Rotem A. A Fatigue Criterion for Fibre-Reinforced Materials. Journal of Composite Materials 1973;7:448-464.

25. Hashin Z. Failure Criteria for Unidirectional Fibre-Composites. Journal of Applied Mechanics 1980;47:329-334.

26. Matzenmiller A, Lubliner J, Taylor RL. A Constitutive Model for Anisotropic Damage in FibreComposites. Mechanics of Materials 1995;20:125-152.

27. Benzeggagh ML, Kenane M. Measurement of Mixed-Mode Delamination Fracture Toughness of Unidirectional Glass/Epoxy Composites with Mixed-Mode Bending Apparatus. Composites Science and Technology 1996;56:439-449.

28. Hwang S, Lie G. Buckling Behaviour of Composite Laminates with Multiple Delaminations under Uniaxial Compression. Composite Structures 2001;53:235-243.

29. Pinho ST, Davila CG, Camanho PP, Iannucci L, Robinson P. Failure Models and Criteria for FRP Under In-Plane of Three-Dimensional Stress States including Shear Non-Linearity. NASA, Langley 2005;NASA/TM-2005-213530.

30. Davila CG, Camanho PP. Failure Criteria for FRP Laminates in Plane Stress. NASA 2003;NASA/TM-2003-212663. 